\title{
Short communication: Long-term survival of flag eartags on an Israeli dairy farm
}

\author{
E. Seroussi, ${ }^{* 1}$ E. Yakobson, ${ }^{\star}$ S. Garazi, $†$ Z. Oved, $†$ and I. Halachmił \\ ${ }^{*}$ Agricultural Research Organization, Institute of Animal Science, Bet-Dagan 50250, Israel \\ †Veterinary Services, Bet Dagan 50250, Israel \\ $\ddagger$ Agricultural Research Organization, Institute of Agricultural Engineering, Bet-Dagan 50250, Israel
}

\section{ABSTRACT}

Two-plated self-piercing eartags were first developed in the 19th century, but information on their retention rates is scarce. A method is presented that facilitates estimation of eartag retention rate by using a random sample of cows that initially had 2 tags (1 on each ear) placed for identification and at least 1 of which survived. Striving to adopt the European Union standard for cattle ear tagging, the Israeli veterinary service conducted a field test to evaluate the performance of plastic eartags under the conditions of a typical Israeli dairy farm. The initial sample ( $\mathrm{n}=900$ cows) was tagged on a single farm. Retention rates were estimated based on the ratio between the observed numbers of cows with 1 or 2 eartags in the surviving group ( $\mathrm{n}=97$ cows). Based on this long-term ( $>3 \mathrm{yr}$ ) field test, the highest yearly retention of flag eartags $(0.89 \pm 0.03)$ was lower than expected (0.98). Tag design and on-farm management were key factors affecting tag retention. A better design of the feedline yoke system in the feeding area, avoiding slits that can entangle the eartags, would help increase tag retention.

Key words: traceability, visual identification, tracking, farm management

\section{Short Communication}

Two-plated, self-piercing eartags were developed in the 19th century as a means of identifying cattle (Boyden et al., 1886). The 2 plates, made of metal or plastic, were placed on each side of the animal's ear and usually carried an identification number. Tags were loaded into an applicator device that, upon closure, punctured the ear and joined the sections of the tag. The tube connecting these sections and securing it to the ear was referred to as the eartag pin. Little information is available in the scientific literature on the yearly retention

Received March 3, 2011

Accepted July 27, 2011.

${ }^{1}$ Corresponding author: seroussi@agri.huji.ac.il rates of eartags; retention rates are highly variable and range from 60 to $98 \%$ depending on the tag features, species, breed, and environmental conditions (Caja et al., 2004). Small eartags such as metal clips were less prone to being torn out than dangling plastic flag tags (Stanford et al., 2001; Caja et al., 2004), although one comparison of the retention of flag and metal clip eartags in cattle led to a conflicting report of $41 \%$ higher retention rate for the plastic flag tags (Belfrage et al., 1990).

Metal tags are difficult to read unless the cattle are firmly restrained; nevertheless, this economically efficient means of marking cattle serves as the official eartag in the National Uniform Eartagging System of the United States (USDA, 2011). In countries of the European Union (EU), on the other hand, tagging with flexible plastic on both ears is mandatory (Byrne, 2004). Moreover, one of these tags should confer visibility from a distance with a size of at least $45 \mathrm{~mm}$ $\times 55 \mathrm{~mm}$ and characters with a minimum height of 5 $\mathrm{mm}$. Considering fonts in the range of 14 to $60 \mathrm{pt}$ and normal visual acuity $(\mathrm{V}=1)$, the maximal legibility distance of these plastic eartags would be 1.3 to 6.7 m, respectively (Sagawa and Kurakata, 2008). Metal clip tags are currently the mandatory system for tagging cattle in Israel (Uzan, 1976). Striving to adopt the EU standard, the Israeli veterinary service conducted a field test to evaluate the performance of plastic eartags under typical Israeli dairy farm conditions (Figure 1).

The specification of the tested tags required flag sizes of 55 to $60 \mathrm{~mm}$ wide by 70 to $75 \mathrm{~mm}$ high. Three companies representing major global manufacturers responded to the request for eartags. The tested eartags were FSG (ITW-Reyflex, Haute-Savoie, France; http:/ www.reyflex.com), OfiCow (Felixcan, Albacete, Spain, http://www.felixcan.com), and TypiFix (Prionics AG, Milan, Italy, http://www.prionics.it). All tags evaluated were of the same basic design comprising 2 flexible polyurethane plates with laser print and a self-piercing and locking pin. Each company tagged 150 animals in both ears, for a total of 900 flag tags tested on one farm, whose management characteristics represented 


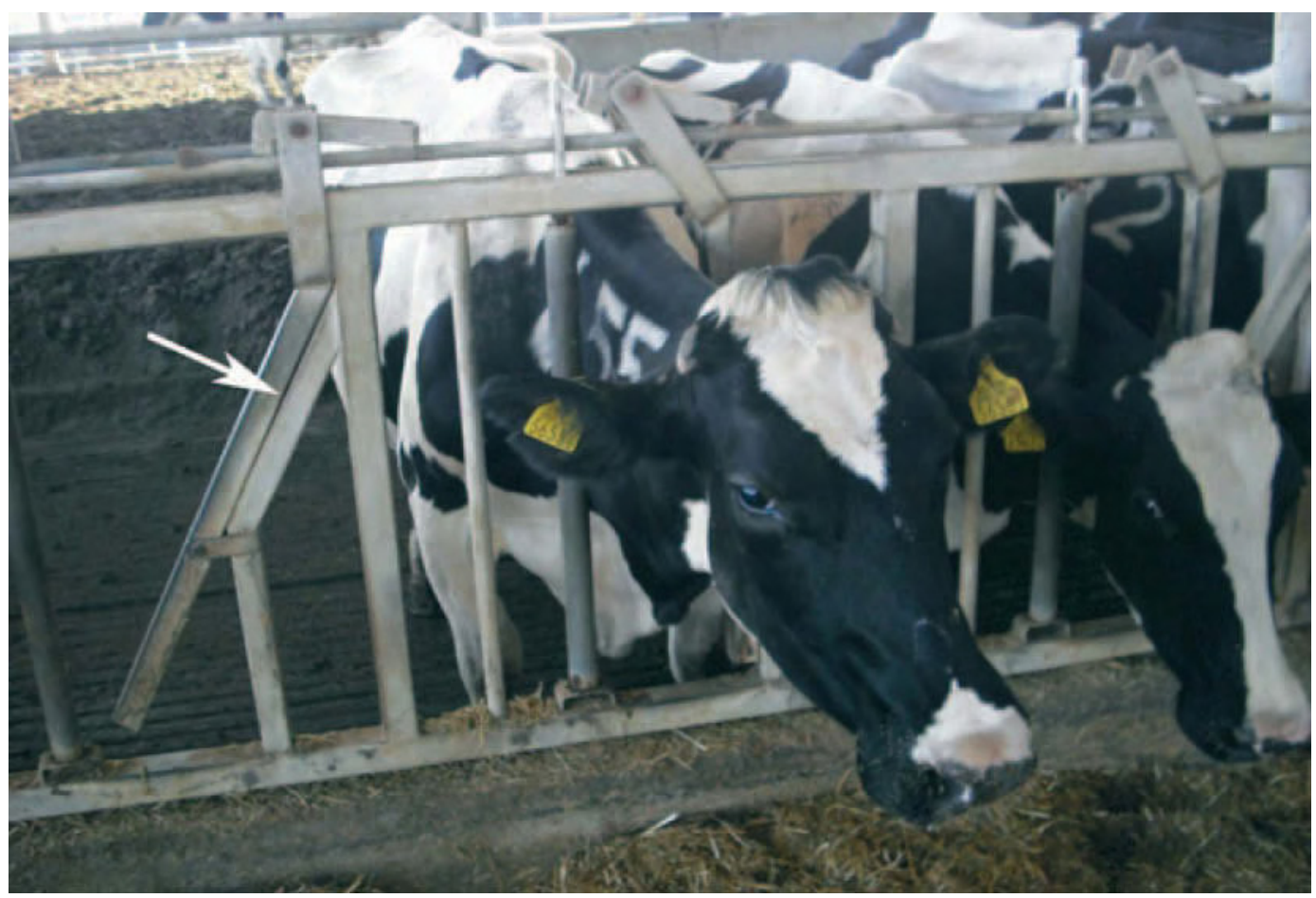

Figure 1. Ear-tagged cows feeding in a yoke system on a typical Israeli dairy farm. Arrow points to a potential entanglement spot for eartags in the slit between the 2 iron bars of the feedline yoke system. Color version available in the online PDF.

the Israeli standards (B. Yakobson, Kimron Veterinary Institute, Bet Dagan, Israel, personal communication). After a period of about $3 \mathrm{yr}(38 \mathrm{mo})$, retention rate $(\mathbf{R})$ was estimated based on the observed number of cows with $1(\mathbf{O})$ or $2(\mathbf{T})$ eartags using the formula $\mathrm{R}=$ $1-\mathrm{O} /(2 \mathrm{~T}+\mathrm{O})$ (equation 4, Seroussi, 2011). Accordingly, the yearly retention rate was $R_{Y}=R^{(1 / Y)}$, with $\mathrm{Y}$ being the duration of the project in years. Assuming that the eartag retention rate had a binomial distribution, the standard deviation (S) would be calculated as $\mathrm{S}=\left[\mathrm{R}^{3} \times(1-\mathrm{R}) / 2 \mathrm{~T}\right]^{1 / 2}$ (equation 5, Seroussi, 2011). In a random sampling, 97 cows with at least 1 eartag were photographed and their eartag status was recorded. The photos were later examined to determine the manufacturer origin and the width of the eartag pin (5 or $7 \mathrm{~mm}$ ).

The retention rate was $89 \pm 3 \% / y r$ for eartag types with a pin diameter of at least $7 \mathrm{~mm}$, and $80 \pm 7 \% / \mathrm{yr}$ for eartags with a pin diameter of $5 \mathrm{~mm}$ (Table 1). The width of the pin likely affected the retention rate of the TypiFix tag, because its manufacturer acknowledged the problem following other field experiments (data not shown). The design was subsequently enhanced by widening the pin to match the width of the competitors' eartags. Thus, a typical flag tag that follows EU standards with a pin designed to snap and not harm the animal in case of eartag entanglement was expected to have a retention rate of $90 \% / \mathrm{yr}$ on an Israeli dairy farm (Table 1). This is lower than both the reported expectation of the 3 manufacturers and the standard of the International Committee for Animal Recording (ICAR), which requires at least $98 \%$ retention for approval (Pauw, 2006). Stanford et al. (2001) suggested that the key factors affecting tag retention are positioning on the ear, size of the tag, proper application of the tag, infection rates, tag design, environmental conditions, period in use, and on-farm management (e.g., feeder design, fence design). The latter, according to farmers who have witnessed cases of eartag entanglement, may be the reason for the high rate of lost tags on the Israeli dairy farm (S. Yaacoby, Volcani dairy farm, Bet Dagan, Israel, personal communication). As

Table 1. Estimated overall $(\mathrm{R})$ and yearly $\left(\mathrm{R}_{\mathrm{y}}\right)$ retention rates of plastic ear tags on an Israeli dairy farm

\begin{tabular}{lcccc}
\hline $\begin{array}{l}\text { Ear tag } p^{1} \\
(\mathrm{~mm})\end{array}$ & $\begin{array}{c}\text { Cows with } \\
2 \text { tags (no.) }\end{array}$ & $\begin{array}{c}\text { Cows with } \\
1 \text { tag (no.) }\end{array}$ & $\mathrm{R}$ & $\mathrm{R}_{\mathrm{y}}$ \\
\hline 5 & 11 & 23 & $0.49 \pm 0.05$ & $0.80 \pm 0.07$ \\
7 & 34 & 29 & $0.70 \pm 0.04$ & $0.89 \pm 0.03$ \\
\hline
\end{tabular}

${ }^{1}$ The ear tags were all tested on one farm and had different pin widths TypiFix (5 mm, Prionics AG, Milan, Italy), FSG (7 mm, ITW-Reyflex, Haute-Savoie, France), and OfiCow ( $7 \mathrm{~mm}$, Felixcan, Albacete, Spain). Retention rates were calculated using a sample of 97 cows that sustained a 38-mo period on the farm. 
shown in Figure 1 (arrow), the typical feedline yoke system contains slits that may be prime locations for entanglement. Based on the estimation of the eartag retention rate presented, adopting the EU standard for flag eartags in the Israeli dairy herd would result in a higher than expected rate of tag loss. A better design of the fence-line feeder, avoiding slits that can entangle the ear tags, might help increase tag retention.

\section{ACKNOWLEDGMENTS}

This work was supported by the Israel Milk Marketing Board. Contribution from the Agricultural Research Organization (ARO), Institute of Animal Science (Bet Dagan, Israel; No. 583/11) is acknowledged. We thank A. Antler (Agricultural Engineering, ARO) for technical assistance.

\section{REFERENCES}

Belfrage, J. B., M. D. Salman, and C. W. S. Lum. 1990. A comparison of the retention of plastic bangle tags and flat metal eartags in cattle. Prev. Vet. Med. 9:155-158.

Boyden, P. M., C. A. Clark, and C. N. Trump, inventors. 1886. Cattle Mark. Assignee, inventors. US Pat. No. 344241.

Byrne, D. 2004. Commission Regulation (EC) No 911/2004 of 29 April 2004 implementing Regulation (EC) No 1760/2000 of the Euro- pean Parliament and of the Council as regards eartags, passports and holding registers. The Commission of the European Communities. Accessed Aug. 18, 2011. http://eur-lex.europa.eu/smartapi/ cgi/sga_doc?smartapi!celexapi!prod!CELEXnumdoc\&lg=en\&num doc $=32004$ R0911\&model $=$ guichett.

Caja, G., J. J. Ghirardi, M. Hernández-Jover, and D. Garín. 2004 Diversity of animal identification techniques: From 'fire age' to 'electronic age'. Pages 21-39 in Development of Animal Identification and Recording Systems for Developing Countries. R. Pauw, S. Mack, and J. Maki-Hokkonen, ed. International Committee for Animal Recording, Rome, Italy.

Pauw, R. 2006. Performance evaluation and approval of official permanent identification devices. Pages 1-13 in International Agreement on Recording Practices, Section 10. International Committee for Animal Recording, Rome, Italy.

Sagawa, K., and K. Kurakata. 2008. ISO standards for accessible design: Development of common basic standards. Gerontechnology (Valkenswaard) 7:202.

Seroussi, E. 2011. The mathematical basis of estimating retention rates of eartags using a random sample of cows that initially had two tags on both ears of which at least one survived. http://cowry. agri.huji.ac.il/Seroussi_et_al2011/EartagRetention.pdf.

Stanford, K., J. Stitt, J. A. Kellar, and T. McAllister. 2001. Traceability in cattle and small ruminants in Canada. Rev. Sci. Tech. Off. Int. Epizoot. 20:510-522.

USDA. 2011. Animal Disease Traceability Framework: Official eartags - Criteria and options. Accessed Sep. 8, 2011. http://www. aphis.usda.gov/traceability/downloads/eartag_listing.pdf.

Uzan A. 1976. Regulations on animal disease (registration, labeling and transportation of cattle). Reshumot 3589. State of Israel, Jerusalem. 